\title{
Collaborative Innovation with External Actors: An Empirical Study on Open Innovation Platforms in Smart Cities
}

\author{
Jukka Ojasalo and Heini Kauppinen
}

\author{
"What is a city, but the people?") \\ True, the people are the city. \\ William Shakespeare (1564-1616) \\ Poet, playwright, and actor \\ In Coriolanus (Act III. Scene I.)
}

\begin{abstract}
Despite the rapid increase of public-private-people partnership (PPPP) programs at the global scale, the scientific knowledge of collaborative innovation in cities is scarce. All smart city initiatives emphasize collaborative innovation for better services and products to address the needs and problems of modern cities. Indeed, there is an evident need for both scientific and practical knowledge in this area. Based on an extensive empirical study of open innovation platforms in smart cities, this article seeks to address this knowledge gap by increasing the knowledge of opportunities and challenges of collaborative innovation between a city and external actors, including companies, third sector organizations, research institutions, and citizens. The opportunities relate to novel services, products, and solutions, as well as economic gains, regional development, and systemic and process improvements. The challenges relate to city governments and external actors.
\end{abstract}

\section{Introduction}

The role of the cities is expanding from the producer and buyer of services into an innovator of services. Increasingly, cities need to initiate, foster, and enable innovation that offers solutions to their needs and problems (Bakici et al., 2013). Urban innovation is at the heart of the concept of a smart city (Caragliu et al., 2011; Hollands, 2008; Komninos, 2002; Shapiro, 2003; Zygiaris, 2013). In today's dynamic and globally networked society, innovation increasingly takes place in collaborative networks. Indeed, cities are facing the challenge of stimulating and orchestrating collaborative innovation in multi-actor networks. Collaborative innovation relates to the larger concept of networked government, which in turn includes not only the effective coordination across government organizations, but also the possible integration of organizations from both the profit and nonprofit sectors into production systems designed to achieve public purposes (Moore, 2009). However, so far, both the scientific as well as pragmatic knowledge of this area is in its infancy. Thus, there is a clear need to increase the knowledge in this field. The present study responds to this need.

The purpose of our empirical study is to increase the knowledge of the opportunities and challenges of collaborative innovation between a city and external actors. External actors include companies, third sector organizations, research institutions, and citizens. This empirical study finds and reports on various opportunities and challenges of collaborative innovation in cities.

The rest of this article is organized as follows. First, based on the literature, we discuss strategies for collaborative innovation, as well as advantages and obstacles/risks of collaborative innovation in the public sector. Then, we explain the empirical method of our study. Next, we describe the opportunities and challenges of collaborative innovation between a city and external actors found in the empirical study. Finally, we draw conclusions. 


\section{Collaborative Innovation with External Actors: Open Innovation Platforms in Smart Cities Jukka Ojasalo and Heini Kauppinen}

\section{Strategies of Collaborative Innovation in the Public Sector}

Collaborative innovation in a smart city context requires an effective strategy for bringing together diverse stakeholders to develop solutions to the city's problems. Harris and Albury (2009) propose four such strategies for opening up innovation in public services to a wider set of actors: i) developing new markets, ii) putting citizens at the heart of services, iii) creating and supporting local "social innovation zones", and iv) strengthening intermediary innovation organizations. Several other researchers have also emphasized the role of innovation intermediaries as a strategy for collaborative public innovation (e.g., Bakici et al., 2013; Braun, 1993; Fung \& Weil, 2010; Stewart \& Hyysalo, 2008). Similar to innovation intermediaries, innovation platforms (or open innovation platforms) represent a strategy for fostering collaborative innovation (Consoli \& Patrucco, 2008; Ojasalo, 2015a, 2015b, 2016; Patrucco, 2011). Ojasalo $(2015 \mathrm{a}, 2015 \mathrm{~b})$ positions an innovation platform as an approach that systematically attracts, facilitates, and orchestrates innovation with external actors with the goal of developing solutions to the platform owners' own problems and needs. In the current research, the platform owner refers to a city.

Eggers and Singh (2009) identify five strategies for public sector collaborative innovation - cultivation, replication, partnership, networking, and open source - that range in focus from generating innovation inside the organization to externally oriented strategies that seek out and leverage promising ideas from elsewhere. These strategies can be placed in a continuum where cultivation is the most internally oriented and open source the most externally oriented. The cultivation strategy engages employees at all levels of a public organization to exchange, develop, and test ideas together. The replication strategy enhances collaborative innovation with other public organizations. The partnership strategy fosters collaborative innovation between public and external partners, which include private companies and nonprofit organizations. The networking strategy utilizes the innovation assets of a diverse base of organizations and individuals to: i) discover, develop, and implement ideas within and beyond organizational boundaries; ii) better capture customer response to services; and iii) create learning organizations. The partnership strategy involves bilateral relationship, whereas the networking strategy is based on multi-actor networks. The open source strategy uses the Internet to attract and enable external and unknown actors to develop solutions to the public sector needs. Partnership, networking, and open source are the strategies that relate to the focus of this article.

Leminen and Westerlund (2015) introduced a fouroption framework for collaborative innovation in cities, which features a matrix based on who is initiating the collaboration (citizen-initiated versus companyinitiated) and what is the target of the collaboration (improving what already exists versus creating something new):

1. Improvement of everyday life and activities: this option is initiated by citizens and aims to improve what already exists. It is supported by offering tangible and intangible resources such as tools and knowledge rather than interfering or steering the activities. Citizens have their own motivations. Innovation outcomes include the ideas and knowledge created by citizens and user communities in real-life contexts.

2. Creative consumer experiences: this option is initiated by citizens and aims to create something new. It is supported by offering tangible and intangible resources such as tools and knowledge. It involves creative and learning activities, as well as novel forms of collaborative activities. The innovation outcomes cover knowledge of emerging needs of citizens and novel forms of open collaboration.

3. Experimentation and implementation of new technologies: this option is initiated by companies and aims to improve what already exists. It is supported by experiments and implementations by offering context, knowledge, and tools. The innovation outcomes of this option are validation of new ideas and prototypes of novel technologies.

4. Creation or re-creation of new business: this option is initiated by companies and aims to create something new. It is supported by using the city as a platform for creating new ideas, where the plurality of stakeholders, knowledge, and ideas come together. The city is a source of ideas as well as a collaboration method between systems and communities. The innovation outcomes are new business opportunities.

Tukiainen and Sutinen (2015) brought forward the model of a city as means to accelerate open innovation. This model offers a holistic view to use collaborative innovation to address several of a city's general 


\section{Collaborative Innovation with External Actors: Open Innovation Platforms in Smart Cities Jukka Ojasalo and Heini Kauppinen}

objectives. Similarly, Tukiainen, Leminen, and Westerlund (2015) discuss the orchestration of a city as a collaborative innovation platform.

Finally, the literature shows that collaborative innovation in the public sector has several advantages compared to in-house innovation, but that - as shown in Table 1 - it also has several obstacles or risks (Bommert, 2010; Hennala et al., 2011; Krogh \& Torfing, 2015; Sørensen \& Torfing, 2011).

\section{Method}

The present empirical findings are based on a study-inprogress dealing with open innovation platforms in smart cities. The research method is qualitative and is based on 32 in-depth interviews (Gummesson, 2000). The interviews were audio recorded and later transcribed. The interviewees were also given the opportunity to make drawings to help express their ideas during the interviews; these drawings were photographed,

Table 1. Advantages and obstacles/risks of collaborative innovation in the public sector

\begin{tabular}{lll}
\hline Author(s) & Advantages & Obstacles/Risks \\
\hline Bommert (2010) & - Idea generation is strengthened & $\begin{array}{l}\text { Potential for one party to impose their own } \\
\text { interest and undermine the pursuit of public } \\
\text { value }\end{array}$ \\
- Idea implementation is facilitated & - Idea diffusion is facilitated & $\begin{array}{l}\text { Distribution and lack of clarity regarding } \\
\text { accountability for public value }\end{array}$ \\
- & May influence the broader socio-political \\
& environment & \\
- Helps to overcome organizational and cultural & restrictions of the innovation cycle
\end{tabular}

Hennala et al. (2011)
- Crossing the borders and distances in an innovation network with expertise, motivation, and creative thinking skills
- Securing the commitment of network collaborators

- Creating a situation in which all parties perceive benefits from the collaboration

- Use of brokers in the innovation process
Sørensen \& Torfing (2011)

- Generation of ideas is spurred

- Selection of ideas is improved

- Implementation of the selected ideas is enhanced

- Dissemination of innovative practices in the public sector is propelled
- Cultural barriers

- Institutional barriers

- Interorganizational barriers

- Organizational barriers

- Identity-related barriers
Krogh \& Tornfing (2015)
- All phases of the innovation process can be strengthened

- The definition of problems and challenges will be more accurate

- Creativity increases in multi-actor collaboration

- The cost/benefit analyses and risk assessments of new solutions is better

- Implementation of the selected solutions is strengthened

- Participating stakeholders act as innovation ambassadors in their own networks
- Difficulties encouraging relevant and resourceful stakeholders to engage in collaboration

- Inability to collaborate productively

- Stakeholders have different professional approaches

- Stakeholders are unable to produce innovative solutions to the problem at hand and the collaborative process becomes "locked" 


\section{Collaborative Innovation with External Actors: Open Innovation Platforms in Smart Cities Jukka Ojasalo and Heini Kauppinen}

collected, and interpreted in the analysis. The informants of the in-depth interview came from Finland (24), Spain (1), Netherlands (2), China (3), Italy (1), and the United States (1). The informants were selected based on their expertise or experience in innovation in cities, public procurement, living labs, or other types of innovation intermediaries in a city context. The interviewees include individuals from city administration, private companies, third sector organizations, innovation intermediaries, as well as from research institutions. Interviewees selected from the city administration had experience or expertise in innovation, urban development, and collaboration with private/third sector organizations. Interviewees selected from the private sector had experience or expertise in collaboration with cities. Interviewees selected from the third sector had experience or expertise in collaboration with cities. Interviewees from innovation intermediaries had experience or expertise in living labs or facilitation of collaborative innovation networks. The researchers were academics who have examined innovation intermediaries or urban development. The interviews each lasted between 1 and3 hours.

In addition to in-depth interviews, we collected material from four co-creative workshops addressing innovation collaboration between cities and external actors. The data from the workshops includes transcriptions, notes, photos of written and drawn material, as well as written summaries of the main conclusions of the workshops. The data were analyzed by open coding and selective coding, following a grounded theory method (Glaser, 1978).

\section{Empirical Findings: Opportunities and Challenges}

Our study identified a number of challenges that arise when a city engages in collaborative innovation with companies, third sector organizations, research institutions, and citizens. In addition to self-evident opportunities and benefits, such as revenues and profits to companies, more efficient services to the cities, and benefits to the society as a whole, we found several unexpected results. The key results are summarized in Table 2 and are described in greater detail in the subsections that follow. The opportunities and benefits relate to novel services/products/solutions, economic gains, regional development, as well as systemic and process improvements. The challenges relate to city government and external actors.
Table 2. Opportunities and benefits and the challenges of collaborative innovation with cities

\section{Opportunities and Benefits}

A. Novel services/products/solutions

1. Unforeseeable innovation potential

2. Open data innovations

3. Sustainable solutions through long-term innovation partnerships

B. Economic gains

1. Cost savings to cities

2. Scalable solutions and services

3. Raising private money for public innovation

4. Better joint proposals for public funding of innovation

\section{Urban and regional development}

1. Favourable publicity and branding of cities and regions

2. Emergence of regional and national innovation clusters

\section{Systemic improvements and process improvements}

1. Learning and knowledge sharing

2. Citizen participation and bottom-up innovation

3. Innovation from the interfaces between actors from different sectors and industries

4. Fostering public-private-people partnerships

5. Potential of coopetition for companies

6. Change of attitudes and enrichment of jobs

7. Sharing city's infrastructure with external actors

8. New opportunities for startups and SMEs

9. Turning the whole city into an innovation platform

\section{Challenges}

E. Challenges of city government

1. Silos in city organizations

2. Slowness of city processes

3. Lack of a systematic approach for cities to foster innovation

4. Reluctance of city organizations and employees to take risks

5. Resistance to change in city organizations

6. Lack of resources in cities

F. Challenges of external actors

1. Negative attitudes of companies towards cities

2. Rivalry set-up of actors

3. Complexity and size of innovation projects 


\section{Collaborative Innovation with External Actors: Open Innovation Platforms in Smart Cities Jukka Ojasalo and Heini Kauppinen}

\section{A. Opportunities and benefits: Novel services/products/ solutions}

1. Unforeseeable innovation potential: Our data show that external input to any innovative process increases the potential to see things from a fresh perspective, which in turn can create unpredictable value and benefits. Cities have large pools of data and knowledge of almost all areas of life. However, the data and knowledge are often buried in organizational silos and they are not exploited most effectively. Often, it is easier for an external party to pinpoint the areas requiring development. These areas may be unforeseeable to the city personnel, but they represent potential innovation. Indeed, innovation platforms enable unexpected encounters, which in turn may lead to new business opportunities, innovation, or at least new perspectives, learning, insights, and ideas. Through collaborative innovation, it is possible to create connections that the parties did not even know might be useful for them. Also, through collaborative innovation, the development ideas from the front-line employees of a city can be utilized more efficiently. Moreover, the establishment of new customer relationships and new revenues becomes possible. The current economic crisis makes way for changes and opportunities to create something new. As the economically difficult times call for transformation, collaborative innovation encourages stakeholders to renew their thinking and actions and provides opportunities for better visibility. The rapid development of technology also enables unforeseen innovation. Furthermore, our data show that students and young citizens are also a potential source of unforeseeable innovation.

2. Open data innovations: Cities receive and store large amounts of various kinds of data as part of their public services. Often, the quantity of the data is large enough to function as "big data" for various digital services. Therefore, the data possessed by a city has great potential to enable a large number of new innovations.

3. Sustainable solutions through long-term innovation partnerships: Scalable solutions, services, and processes foster sustainability. Collaborative innovation enhances the usage of resources and, in the long term, enables resource savings. Sustainable and profitable services that consider the interest of all stakeholders can be designed more easily through collaborative innovation. Collaborative innovation enables the city to develop various preventive services and thus create sustainability. It also enables them to think differently about the production and consumption of public services, and to innovate services that will reduce costs and save resources over time. Long-term collaboration would enable better partnerships and more efficient production of services while adding to customer understanding.

\section{B. Opportunities and benefits: Economic gains}

1. Cost savings to cities: Collaborative innovation in cities brings about cost savings in several ways. First, if the innovation network developing the solution involves several cities, they can share the development costs. Second, if several cities adopt the same innovation, it increases the production volume, enables economies of scale, and is likely to decrease the price. Third, if several cities adopt the innovation, they can also share the maintenance costs.

2. Scalable solutions and services: Collaborative innovation has a clear potential to result in solutions and services with substantial scalability. This also applies to process innovation and best practices. Scalability means more business opportunities, even internationally. With good scalability, the benefits of the innovation can be disseminated within the same city to different departments or different parts of the city, to other the cities home, or even abroad. The public sector has potential to act as a dynamic engine of scalable innovation because it does not have a commercial interest itself. In contrast, scalability in the private sector may remain modest and diffusion of innovation may be slow because companies tend to hide information and carefully protect their intellectual property rights and innovations through patents and other mechanisms. The public sector may, therefore, be a forerunner of scalable innovation. Many of a cities' problems and needs are universal. Consequently, an innovation developed for the needs of one city has potential for substantial scalability. If one of the cities of the collaborative innovation network adopts the innovation, this functions as a favorable reference with other potential cities. Already, the fact that the solution was developed in collaborative innovation involving a city is a good reference. A city may also offer its contacts to enhance the diffusion of the innovation to other cities.

3. Raising private money for public innovation: It is in the interest of cities if new services and solutions can be developed without tax money. The current politic- 


\section{Collaborative Innovation with External Actors: Open Innovation Platforms in Smart Cities Jukka Ojasalo and Heini Kauppinen}

al mindset in most Western countries is that the cities should not strive to develop and produce everything themselves, but rather should aim to trust external partners to develop an increasing share of service innovation and production. Collaborative innovation represents a clear opportunity for this development.

\section{Better joint proposals for public funding of innova-} tion: Various funding opportunities exist for innovation for in cities. If an innovation project receives external funding from national or international sources - for example from the European Union's Horizon 2020 programme (https://ec.europa.eu/programmes/horizon2020/) - the city will save its own tax money. Better funding proposals with higher likelihoods of acceptance are likely to emerge from collaborative innovation networks. Networking and co-operation create stronger joint ventures by combining the different perspectives and strengths of each party. This approach may lead to more impressive projects and better innovation.

\section{Opportunities and benefits: Urban and regional development}

1. Favourable publicity and branding of cities and regions: Successful collaborative innovation allows favourable publicity and branding. People make the change happen. Positive word-of-mouth communication can lead to an improved city brand, and it does not necessarily require large investments moneywise. Taking part in cutting-edge collaborative innovation "gets the city noticed" through favourable publicity. This approach can be a means to brand a city, create a certain image for the city, and increase its reputation. Innovation network partners can evoke publicity that benefits all parties through, for instance, social media. Success stories can even receive international attention and thus help in internationalization and investors attraction. Advocates of collaborative innovation can be used for enhancing the attractiveness of all parties. Good publicity on forerunner innovation will boost the marketing efforts of all parties involved: the city, the companies, and the research and education institutions.

\section{Emergence of regional and national innovation} clusters: Larger innovation clusters enable the expansion of markets. Any technical interface can be similar between the cities, making them easier for external actors to embrace. Similar interfaces to city systems make business planning and benchmarking between the cities easier for companies. Thus, cities can join forces and create common interfaces for services, which consequently enhances the emergence of regional and national innovation clusters. An innovation platform facilitating collaborative innovation can be owned by several cities instead of one. Several owners provide more efficient, larger-scale learning, enhanced scaling of operations, and more efficient organization of activities. Also, the social responsibility of all the stakeholders can be more easily addressed. Combining forces also means that structural funding could be exploited more efficiently.

\section{Opportunities and benefits: Systemic improvements and process improvements}

1. Learning and knowledge sharing: Our empirical data suggest that a city could function in a sparring role, thereby enabling dialogue, confluence, and experimentation with different actors in order to create innovation. A culture of experimentation leads to learning and the growth of experience. Experimenting enables the creation of a working model of how the innovation process could function for collecting best practices and lessons learned. Experimental test cases show what works and what does not in reality. Learning from observed failures in the pilot phase represents an opportunity to improve an innovation. Also, sharing the knowledge eases the burden that each party would otherwise have to bear on their own. The incentive to collaborate comes from the realization that everyone benefits, at least in terms of learning and new insights. The parties learn from and with each other. Those who are involved in collaborative innovation have the potential to get one step ahead of those that are not. In addition to the learning gains to actors involved in collaborative innovation, all of society is eventually the beneficiary. Benchmarking the competing service providers enhances one's own services as well.

2. Citizen participation and bottom-up innovation: An open innovation platform enables the involvement of user communities on a larger scale and offers visibility, thereby creating opportunities for bottom-up innovation. The more the citizens are enabled to affect the outcomes, the more interested they become in participating. Although citizens may not think about the business opportunities for innovations, they are often very interested in developing and renewing their own urban living environment, which motivates them to contribute to the innovation process. Our data show that citizens and third sector organizations can also be trusted to lead their own projects. 


\section{Collaborative Innovation with External Actors: Open Innovation Platforms in Smart Cities Jukka Ojasalo and Heini Kauppinen}

\section{Innovation from the interfaces between actors from} different sectors and industries: Often, the most fruitful innovations emerge through interactions and collaboration between different kinds of actors. Innovation projects for a city's needs often involve companies from different industries, including both large and small companies, third sector organizations, universities and other research institutions, citizens, and other cities. Such multi-actor innovation consortia have great potential for creating entirely new kinds of services, products, and solutions - even disruptive innovations.

\section{Fostering public-private-people partnerships:} There is an evident need for different options for public services and their future innovation and production. Public-private-people partnership (PPPP) is an increasingly popular approach for this purpose. Collaborative innovation enhances PPPP in general, which in turn may bring several benefits to all parties. It is important for the parties to understand each other's differences and make use of them. Encounters have to be regular and open in nature in order to build trust. Collaboration needs to be nourished and clear approaches for innovation through PPPP are required. Such approaches may be innovation platforms and intermediary organizations that systematically facilitate innovation in such partnerships.

5. Potential of coopetition for companies: Coopetition refers to a situation where two organizations both compete and cooperate with each other (Bengtsson \& Kock, 2000). Collaborative innovation may give an opportunity to companies as well as the cities - that usually compete with each other- to engage in mutually beneficial collaboration. Coopetition between companies and between cities can lead to vitality and new innovations, creating benefits for the cities, regions, and nations. Coopetition can push actors to higher levels of performance.

6. Change of attitudes and enrichment of jobs: Collaborative innovation can change attitudes and create a more enthusiastic atmosphere in the daily work of city employees. Constant communication and co-operative work may positively affect working capacity in a positive manner and make people more efficient. Increasing knowledge and learning new things can lead to the realization of innovations as opportunities for a better future. Through collaborative innovation, city workers can be involved in innovation work and in implementing their own goals. Such activities can make them feel that they are doing something more relevant than their usual day-to-day tasks. Participating in co-creative workshops, for instance, can give the feeling of success as the real problems (from their point of view) are being tackled.

7. Sharing city's infrastructure with external actors: Many companies and third sector organizations are interested in learning, knowing, and utilizing their city's infrastructure. Sharing their city's infrastructure provides them with new resources for their existing and potential business. It also allows them to learn about the city, which has the potential to increase their competitiveness when serving their private sector customers as well as the city itself.

8. New opportunities for startups and SMEs: Startups and SMEs are often overshadowed by larger companies. Collaborative innovation creates more opportunities for smaller companies and enables them to show and prove their skills as well as to exploit of their niche know-how. Smaller actors are usually more agile, flexible, and open-minded, which fosters an experimental culture. Startups also tend to be more willing to experiment in innovation. An innovation platform and networks can offer support, mentoring, assistance in marketing and sales-oriented operations, and other resources, which are often scarce in small companies. Partnering opportunities and matchmaking are vital for smaller actors, and innovation platforms can help connect them with larger actors. In turn, smaller companies stimulate the larger ones to do things differently.

\section{Turning the whole city into an innovation platform:} A city as an innovative platform offers opportunities for developing new solutions in an agile manner and is a basis for competitiveness. The city infrastructure, processes, and special events can be designed to allow experimentation and innovation. This approach affects the attractiveness and economy of the city as well as the whole region. Successful cities attract people, companies, and investors. Different challenges and competitions with prizes and awards arranged by the city are a great way to engage people and businesses to innovate for the city. New business opportunities can arise through competitions. Embracing an innovation atmosphere lowers the barrier to external actors to recognize and take part in solving a city's challenges. 


\section{Collaborative Innovation with External Actors: Open Innovation Platforms in Smart Cities Jukka Ojasalo and Heini Kauppinen}

\section{E. Challenges of city government}

1. Silos in city organizations: Cities have the historical and legislative burden of being organized into departments, which tend to "protect their own turf" from outsiders. Thus, other departments within a city as well external actors outside that city may have very little influence on the decision making and function of the department. Also, the role of professions and the professional identity of employees is often strong within city organizations. This also enhances the silo effect. Consequently, this all may prohibit the innovativeness of a department in several ways:

- The department may not be aware of the end user needs and may lack deep customer understanding. Most importantly, they may not see existing problems and needs holistically from the customer perspective. They may often see just one aspect or symptom of the problem. For example, when citizens and companies deal with a city, they often have to go from one department to another to get all the aspects of their problem covered.

- Several innovations require multi-sectoral collaboration. If the collaboration between the departments is stiff, their innovation potential remains modest.

- The department may have an extensive body of data and knowledge that has accumulated in their area. However, the department may not understand the potential value of the information for innovation. If an external actor - a company, for example - or some other city department had access to the data or knowledge, they may be able to exploit it for innovation.

- City employees are often obligated to primarily think about the objective of their own department and secondarily think about the larger objectives and needs of the city. Thus, their job encourages them to "think inside the box." This limitation often results from the "management by results" approach implemented in cities, which has resulted in sub-optimization.

- Attitudinal reluctance to disturb the existing status quo within the city cements the stagnation that limits innovation. Collaboration between departments is difficult because people make sure not to "step on each other's toes" and cause additional trouble. This reluctance stems from the existing culture in public administration, which has long historical roots.
- Actors outside one's own department are often perceived as "enemies" rather than potential partners for collaboration. This is a large obstacle to innovation and a lost opportunity because the most fruitful innovation activities often take place at the interface of silos.

2. Slowness of city processes: The decision making and processes of a city are perceived to be too slow for the requirements of dynamic innovation in general. Slowness is often referred as "bureaucracy". The public sector must operate in terms of legislation in their decision making because of their regulatory responsibilities. Regulatory responsibility might require longer decision-making processes. Often, companies do not understand that cities are obligated to move slowly. In this sense, they are different by their nature. For a city, a year may be a normal or even considered a short timescale for decision making, but for a startup company interested in collaborative innovation, it may be an eternity.

3. Lack of a systematic approach for cities to foster innovation: Our study found that city employees recognize the need to foster innovation. However, the methods for doing so are still lacking. City officials often see problems that might be promising starting points for commercial innovation. However, there are no systematic approaches for how to turn the problem in hand into an innovation process that would hopefully result in a commercial service or product. In other words, city officials lack methods to help turn problems into products. The knowledge of the problem remains within the city hall and an opportunity for innovation is lost. City officials would need a systematic approach to deal with this issue. The approach should address the following questions: What is the process for dealing with a problem representing a potential innovation? How is the problem defined? Who covers the costs? What resources are required? Who takes the risk? Which city departments exploit the result? Consequently, the following challenges arise in the city hall in an attempt to turn a problem into a product: i) goal sharing challenges between city departments, ii) process management challenges, iii) organizational challenges for cross-departmental collaboration, iv) resource allocation challenges, and v) reporting challenges.

4. Reluctance of city organizations and employees to take risks: Risk aversion is often caused by the fear of failure, the fear of losing one's job, or the fear of ruin- 


\section{Collaborative Innovation with External Actors: Open Innovation Platforms in Smart Cities Jukka Ojasalo and Heini Kauppinen}

ing one's reputation. The logic is that, if risks are not taken, then failures will not occur. City employees might not be willing to take risks for fear of misconduct. It is easier to stick to old habits and procedures. Also, a company's willingness or ability to take risks might also be low. Positioning relative to the competition is one of the forces that leads to reluctance. Moreover, the willingness to take risks depends on how much money and resources are needed. A city's ability to take risks can also be affected by the regulatory responsibilities it has for the success of a service. If a service is seen as a failure, a city might be responsible for taking corrective actions immediately. Furthermore, ambiguity around risk sharing can have an effect on the willingness to take risks.

5. Resistance to change in city organizations: Change resistance is often mentioned as a significant challenge to overcome, and it can even override good change leadership. This resistance concerns the attitudes of employees and is linked to above-mentioned fear and reluctance to take risks. There are also mental barriers to overcome. Strong bureaucracy and silos add to this phenomenon. The existing mode of operations is very hard to change. Additionally, change resistance can add to the impression of slow city processes. Our study findings call for a change of attitudes, a culture change, and efforts to reduce resistance to change. However, even though change leadership is often needed, it may not be effectively implemented.

6. Lack of resources in cities: Resources, mainly human or monetary, are perceived to be limited. Development and innovation work is seen as dependent on humans. Scarcity of resources and cutting existing resources is seen as a common challenge. Additionally, lack of resources is seen as a limitation to any innovation work. Recruiting more resources is banned on many occasions. Resources allocated for development work are small and continue to diminish. At the same time, the use of external consultants is often criticized. Working hours are always expensive and represent a large part of any project's budget. Lack of resources is often used as an excuse for not investing in innovation or development. Resource allocation is a challenge on its own. There is also a lack of knowledge about how to use the resources wisely. Reorganizing resources could help solving this problem.

\section{F. Challenges of external actors}

1. Negative attitudes of companies towards cities: In our study, some companies appeared to hold peculiar attitudes towards city organizations. Cities are often seen as less attractive partners for collaboration. Companies might lack understanding about a city organization's processes and functionality. Additionally, smaller companies or startups might not be interested in solving problems for cities due to perceptions about city processes being too stiff and slow. Often, companies do not realize that cities are partners of a different kind than private companies. They do not know or do not like the fact that cities need to follow legislation and policies in their decision making and processes.

2. Rivalry set-up of actors: Both cities and companies tend to compete against each other, meaning that cities compete against other cities and companies against other companies. Cities are facing very similar challenges and it seems unnecessary that all of them would "reinvent the wheel" time after time. Currently, it is not an easy job to establish collaboration, either between cities or between companies. This rivalry set-up appears to be affecting opportunities for open collaborative innovation. However, it is commonly recognized that collaboration and sharing would, indeed, yield more benefits and create more opportunities for innovation.

3. Complexity and size of innovation projects: Large and complex projects may turn out to be a barrier to innovation and exclude smaller partner candidates. Trying to implement large ensembles can also turn out to be slow and strenuous while making the holistic viewing of the overall project more difficult. Complex projects could be split into smaller parts instead. Also, attempts to forecast the future and make perfect plans without possibilities for flexibility or changing the plans are blocking innovation possibilities. This challenge is also faced by the city governments.

\section{Conclusion}

The purpose of this empirical article was to increase the knowledge of the opportunities and challenges of collaborative innovation between a city and external actors. Several practical implications stem from the present empirical findings. On one hand, our study shows that the city, as well as the external actors, may 


\section{Collaborative Innovation with External Actors: Open Innovation Platforms in Smart Cities Jukka Ojasalo and Heini Kauppinen}

receive several significant and novel gains from collaborative innovation. Cities have subtantial hidden potential to enhance services for their citizens, generate new business for companies, and grow competitive regional ecosystems. On the other hand, it shows the variety of challenges and risks that need to be overcome to materialize the benefits.

The findings encourage cities to orchestrate and enable co-creative interaction between actors from different backgrounds and industries. Our study shows that cities should enhance networking in general, even if there are no clear goals in mind at the outset. Such multi-actor networking holds potential to eventually result in novel, unforeseeable innovation. Moreover, cities increasingly open up their data to be freely used by anyone. The data itself is raw material, but it enables innovation for various new services. In addition to opening up the data, cities should actively facilitate and stimulate external actors for collaborative innovation to exploit the opportunities of their data for profitable business and new services. Also, most cities are committed to supporting sustainable development. Cities can have a great impact on sustainable development in many ways, for example, due to their high procurement volumes. However, effective sustainable solutions often require holistic approaches and innovative multi-actor collaboration, both within the city government and with external actors in the region. However, to be effective, the collaborative innovation needs to be undertaken over the long term. Indeed, cities should more actively orchestrate large-scale and long-term sustainable innovation in multi-actor settings.

Orchestrating collaborative innovation requires effort from the city, however, our study suggests that the resulting gains are likely to exceed the costs of such efforts. Collaborative innovation has the potential to result in cost savings of service development and production. If the companies see the opportunity as attractive, they will invest in the innovation and thus share development costs. Similarly, consortia with reliable and innovative partners are more likely to receive public funding for the development and experimentation costs. Potential for scalability is a major gain from collaborative innovation with cities, while cities have similar problems and needs. A breakthrough solution in one city may easily be scalable in many other, both home and abroad. This is a clear incentive for companies to participate in collaborative innovation.

Cities such as Amsterdam and Barcelona have successfully branded themselves as leading smart cities. Collab- orative innovation is always one of the most important building blocks of the smart city story and brand. Indeed, real-life success stories on collaborative innovation significantly help a city in building up its brand. A strong city brand gives several advantages to a city: it attracts companies, talented people, and research institutions, thus creating more jobs and economic growth. As a result, new industries and knowledge clusters may emerge in the region.

Collaborative innovation has the potential to make several systemic and process improvements within a city. Traditionally, the products and services procured by the city from companies are already in the commercial phase, in other words, they are ready to be used. Through collaborative innovation, the role of the city changes from buyer into stimulator and orchestrator of innovation. This means that the city expands its activity to the pre-commercial phase. This shift enables the culture of learning, knowledge sharing, and experimentation to grow in the city government. Fostering participatory democracy at the grassroots level is an increasing systemic change of modern urbanization development. Indeed, even though the collaborative innovation did not result in commercial product or service, it gives citizens the opportunity to improve their quality of life in concrete ways. Moreover, involvement in bottom-up innovation gives citizens a sense that they are listened to and can directly make a difference in mundane issues. In addition, digitalization and multichannel communication open up new ways to organize citizen participation in collaborative innovation and public-private-people partnership projects.

Cities are responsible for many large-scale issues that require holistic solutions, which typically require input from different industries. When actors from different industries come together in collaborative innovation, there is potential for novel solutions. With the right orchestration of collaboration, cities can catalyze radical and future-oriented innovation. This approach may include coopetition (where competitors collaborate), which may take place both between companies and between cities. As a result of collaborative innovation, the attitudes of people in city government may change from bureaucratic into innovative and experimental. This may enrich their jobs and increase their job satisfaction.

Cities possess plenty of valuable and multi-functional infrastructure, such as public spaces, hospital infrastructure, and recreational facilities. However, typically, the capacity of city infrastructure is just partly 


\section{Collaborative Innovation with External Actors: Open Innovation Platforms in Smart Cities Jukka Ojasalo and Heini Kauppinen}

utilized. Through collaborative innovation, the opportunities of the sharing economy can be materialized to increase the capacity utilization of the city infrastructure. SMEs, third sector organizations, and citizens may develop business models and services based on renting the infrastructure, instead of extensive investments. Eventually, the whole city can be turned into an innovation platform with a new attitude of collaborative innovation and experimentation in the city government.

Several avenues for further research and policy recommendations emerge from our study. First, new governance system for cities should be developed and experimented with in the context of collaborative networked innovation. This should be conducted with both scientific research and piloting. Second, cities should develop and experiment with new ways of lean and agile collaborative innovation based on rapid testing and learning (Ojasalo \& Ojasalo, 2015a, 2015b). Third, more research is required to develop approaches and scenarios for open innovation platforms and innovation intermediaries facilitating the collaborative innovation of cities.

\section{About the Authors}

Jukka Ojasalo is a Professor and current Head of the Master of Business Administration Degree Programme at Laurea University of Applied Sciences in Finland and Adjunct Professor at Aalto University School of Business and Helsinki University Faculty of Social Sciences. He completed his $\mathrm{PhD}$ at Hanken Swedish School of Economics and Business Administration in Helsinki, Finland in 1999. Previously, he was Professor of Marketing at Lappeenranta University of Technology as well as at Turku School of Economics and Business Administration. Prior to his academic career, he worked for several years in the IT industry and for the Finnish government. He has published two textbooks and many articles on service, customer relationships, networks, and innovation.

Heini Kauppinen is an experienced service design professional who holds an MBA from Laurea University of Applied Sciences in Finland. As a student, she was a member of the research group for this study the opportunities and challenges of collaborative innovation between a city and external actors. Her work and research interests include service innovation and design, co-creation, and project management.

\section{References}

Aoki, M. 2001. Types of Relational Financing and the Value of Tacit Knowledge. In M. Aoki, A. Greif, \& P. Milgrom (Eds.), Toward $a$ Comparative Institutional Analysis: 307-309. Cambridge, MA: MIT Press.

Bakici, T., Almirall, E., \& Wareham, J. 2013. The Role of Public Open Innovation Intermediaries in Local Government and the Public Sector. Technology Analysis \& Strategic Management, 25(3): 311-327.

http://dx.doi.org/10.1080/09537325.2013.764983

Bengtsson, M., \& Kock, S. 2000. "Coopetition” in Business Networks To Cooperate and Compete Simultaneously. Industrial Marketing Management, 29(5): 411-426.

http://dx.doi.org/10.1016/S0019-8501(99)00067-X

Bommert, B. 2010. Collaborative Innovation in the Public Sector. International Public Management Review, 11(1): 15-33.

Braun, D. 1993. Who Governs Intermediary Agencies? Principal-Agent Relations in Research Policy-Making. Journal of Public Policy, 13(2): 135-62.

https://doi.org/10.1017/S0143814X00000994

Caragliu, A., Del Bo, C., \& Nijkamp, P. 2011. Smart Cities in Europe. Journal of Urban Technology, 18(2): 65-82.

http://dx.doi.org/10.1080/10630732.2011.601117

Consoli, D., \& Patrucco, P. P. 2008. Innovation Platforms and the Governance of Knowledge: Evidence from Italy and the UK. Economics of Innovation and New Technology, 17(7): 701-718. http://dx.doi.org/10.1080/10438590701785694

Eggers, W., \& Singh, S. K. 2009. The Public Innovator's Playbook: Nurturing Bold Ideas in Government. Winnipeg, Canada: Deloitte, Harvard Kennedy School, Ash Institute for Democratic Governance and Innovation, Printcrafters.

Fung, A., \& Weil, D. 2010. Open Government and Open Society. In D. Lathrop \& L. Ruma (Eds.), Open Government: Collaboration, Transparency, and Participation in Practice: 105-112. Sebastopol, CA: O'Reilly Media.

Glaser, B. G. 1978. Theoretical Sensitivity. Mill Valley, CA: The Sociology Press.

Gummesson, E. 2000. Qualitative Methods in Management Research. London: Sage Publications.

Harris, M., \& Albury, D. 2009. Why Radical Innovation Is Needed for the Recession and Beyond: The Innovation Imperative. Nesta Discussion Paper. London: Nesta.

Hennala, L., Parjanan, S., \& Uotila, T. 2011. Challenges of Multi-Actor Involvement in the Public Sector Front-End Innovation Processes: Constructing an Open Innovation Model for Developing WellBeing Services. European Journal of Innovation Management, 14(3): 364-387.

http://dx.doi.org/10.1108/14601061111148843

Hollands, R. G. 2008. Will the Real Smart City Please Stand Up? City, 12(3): 303-320.

http://dx.doi.org/10.1080/13604810802479126

Howells, J. 2006. Intermediation and the Role of Intermediaries in Innovation. Research Policy, 35(5): 715-728.

http://dx.doi.org/10.1016/j.respol.2006.03.005 


\section{Collaborative Innovation with External Actors: Open Innovation Platforms in Smart Cities Jukka Ojasalo and Heini Kauppinen}

Komninos, N. 2002. Intelligent Cities: Innovation, Knowledge Systems and Digital Spaces. London: Spon Press.

Krogh, A. H., \& Torfing, J. 2015. Leading Collaborative Innovation: Developing Innovative Solutions to Wicked Gang Problems. In A. Agger, B. Damgaard, A. H. Krogh, \& E. Sørensen (Eds.), Collaborative Governance and Public Innovation in Northern Europe: 91-110. Oak Park, IL: Bentham Scientific Publisher.

Leminen, S., \& Westerlund, M. 2015. Cities as Labs: Towards Collaborative Innovation in Cities. In P. Lappalainen, M. Markkula, \& H. Kune (Eds.), Orchestrating Regional Innovation Ecosystems: 167-175. Finland: Aalto University, Laurea UAS, and Built Environment Innovation RYM Ltd.

Moore, M. H. 2009. Networked Government. In S. Goldsmith \& D. Kettle (Eds.), Unlocking the Power of Networks: Keys to HighPerformance Government: 190-228. Washington, DC: Brookings Institution Press.

Muegge, S. 2011. Business Ecosystems as Institutions of Participation: A Systems Perspective on Community-Developed Platforms. Technology Innovation Management Review, 1(2): 4-13. http://timreview.ca/article/495

Ojasalo, J. 2015a. Open Innovation Platform in a Smart City: Empirical Results. The Journal of American Business Review, Cambridge, 4(1): 195-202.

Ojasalo, J. 2015b. Open Service Innovation Platform in a Smart City. In P. D. Renata \& L. Beltrametti (Eds.), Proceedings of the 10th ECIE European Conference on Innovation and Entrepreneurship: 521-528. Genoa, Italy.

Ojasalo, J. 2016. Building An Open Service Innovation Platform For a City's Needs: An Empirical Study On Smart Cities. In L. G. Chova, A. L. Martínez, \& C. I. Torres (Eds.), Proceedings of the 10th International Technology, Education and Development Conference (INTED2016): 6172-6181. Valencia, Spain: IATED Academy.

Ojasalo, J., \& Ojasalo, K. 2015a. Using Service Logic Business Model Canvas in Lean Service Development. In Proceedings of the 2015 Naples Forum on Service, June 9-12, 2015, Naples, Italy.
Ojasalo, J., \& Ojasalo, K. 2015b. Service Logic Business Model Canvas for Lean Development of SMEs and Start-Ups. In N. Baporikar (Ed.), Handbook of Research on Entrepreneurship in the Contemporary Knowledge-Based Global Economy: 217-243. Hershey, PA: IGI Global.

Patrucco, P. P. 2011. Changing Network Structure in the Organization of Knowledge: The Innovation Platform in the Evidence of the Automobile System. Economics of Innovation and New Technology, 20(5): 477-493.

http://dx.doi.org/10.1080/10438599.2011.562356

Shapiro, J. M. 2003. Smart Cities: Explaining the Relationship between City Growth and Human Capital. Cambridge, MA: Harvard University.

Stewart, J., \& Hyysalo, S. 2008. Intermediaries, Users and Social Learning in Technological Innovation. International Journal of Innovation Management, 12(3): 295-325. http://dx.doi.org/10.1142/S1363919608002035

Sørensen, E., \& Torfing, J. 2011. Enhancing Collaborative Innovation in the Public Sector. Administration \& Society, 43(8): 842-868. https://doi.org/10.1177/0095399711418768

Tukiainen, T., Leminen, S., \& Westerlund, M. 2015. Cities as Collaborative Innovation Platforms. Technology Innovation Management Review, 5(10): 16-23. https://timreview.ca/article/933

Tukiainen, T., \& Sutinen, P. 2015. Cities as Open Innovation Platforms for Business Ecosystems. In P. Lappalainen, M. Markkula, \& H. Kune (Eds.), Orchestrating Regional Innovation Ecosystems: 313-322. Espoo, Finland: Aalto University, Laurea UAS, and Built Environment Innovation RYM Ltd.

Zygiaris, S. 2013. Smart City Reference Model: Assisting Planners to Conceptualize the Building of Smart City Innovation Ecosystems. Journal of the Knowledge Economy, 4(2): 217-231. http://dx.doi.org/10.1007/s13132-012-0089-4

Citation: Ojasalo, J., \& Kauppinen, H. 2016. Collaborative Innovation with External Actors: An Empirical Study on Open Innovation Platforms in Smart Cities. Technology Innovation Management Review, 6(12): 49-60. http://timreview.ca/article/1041

Keywords: collaborative innovation, public innovation, smart city, innovation intermediaries, innovation platform, PPPP, public-private-people partnership, urban development, collaboration 